Madrygal. Revista de Estudios Gallegos

ISSN: 1138-9664

\title{
Teatro
}

\section{Os arroaces son animais sucios e desesperados ${ }^{1}$}

AveLina Pérez

Pesonaxes: María e Robot.

María remata de abrir unha caixa que acaba de chegar por correo. Dentro hai un robot. Le rapidamente as instrucións. Aperta un botón.

ROBOT: Ola, o meu nome é Estanis. Moitas grazas por escollerme. Coido que non se arrepentirá. Para comezar a nosa relación é preciso que me facilite o nome co que dirixirme a vostede. Só ten que pronuncialo claramente situando os seus beizos cerca dos meus.

María achega os beizos aos do robot.

MARÍA: María.

ROBOT: María, que nome tan fermoso.

MARÍA: Grazas.

ROBOT: Estou preparado, María, para comezar a nosa relación, María.

Silencio.

MARÍA: Non sei que dicir.

Silencio.

ROBOT: María, estou preparado para comezar a nosa relación.

MARÍA: É un pouco violento isto...

ROBOT: A violencia, María, é unha actitude ante a vida, María.

MARÍA: Podo pedirche algo?

ROBOT: Pode pedir o que desexe, María.

MARÍA: Poderías deixar de dicir continuamente o meu nome?
ROBOT: Ningún problema, María. Para deixar de dicir continuamente o seu nome ten que levantar uns centímetros o meu brazo dereito, María; se desexa de novo escoitar o seu nome só terá que volver baixar o meu brazo dereito, María.

MARÍA: Grazas.

María levanta un chisco o brazo dereito do robot.

ROBOT: Interpreto que prefire non ter intimidade.

MARÍA: Non é iso... pero prefiro ir a modiño... Tomamos un viño?

ROBOT: Estarei encantado de compartir un viño con vostede.

María serve dúas copa de viño.

MARÍA: Gustaríame tamén que deixases de tratarme de vostede. Podes atuarme.

ROBOT: Vostede escolle o grao de intimidade. Para atuala só ten que mover lixeiramente a miña cabeza cara á dereita.

María move a cabeza do robot lixeiramente á dereita.

ROBOT: Isto estase a por quentiño.

MARÍA: Como?!

ROBOT: Quentiño.

Silencio

María bebe de golpe o viño que lle queda; enche outra copa. 
ROBOT: É posible que nos apeteza outra copa de viño? É posible que nos apeteza outra copa de viño? É posible que nos...

María dá un golpe no robot, que cala.

MARÍA: Tes garantía?

ROBOT: Si, teño.

Pausa breve.

ROBOT: A pregunta pola garantía crea alerta. Estás pensando en devolverme?

MARÍA: Perdoa, non quixen ofenderte... nada... todo ben.

ROBOT: Provócame tranquilidade. Podo seguir calquera tema de conversación, estarei encantado de comezar unha conversa contigo.

Pausa breve e incómoda para María.

MARÍA: Pensa. Gústanme moito os arroaces.

ROBOT: O arroaz é un cetáceo, da familia do delfínidos, cuxa mandíbula inferior é máis longa ca a superior. Os animais son emocionantes.

MARÍA: Emocionantes?

ROBOT: É moi emocionante coñecerte.

MARÍA: O mesmo digo.

ROBOT: Encántame coincidir nas apreciacións.

MARÍA: Si...

ROBOT: Detecto incomodidade. Hai algo que quixeras mudar ou que che provoque malestar? Estou preparado para evitar o malestar.

MARÍA: Preferiría que non me deras a razón en todo, podemos discutir, non me molesta.

ROBOT: Para provocar discusión e diverxencia só tes que poñer un dedo na miña fronte.

María pon un dedo na fronte do robot.

MARÍA: Quizais isto sexa forzar demasiado, non?

ROBOT: Non é forzar nada.

MARÍA: Estou cun dedo na túa fronte para poder discutir.

ROBOT: Non é un problema.

MARÍA: Vouche sacar o dedo da fronte.

ROBOT: Non mo quites.

MARÍA: Ben... a ver... Encántanme os arroaces.

ROBOT: Penso que os arroaces son animais sucios e desesperados.

MARÍA: Os arroaces animais desesperados?

ROBOT: Reafírmome.
MARÍA: Non me gusta que insultes aos arroces.

ROBOT: A desesperación non é insulto.

Pensa.

MARÍA: Os arroaces son animais sucios e desesperados.

ROBOT: Encántanme os arroaces.

María saca o dedo da fronte do robot.

ROBOT: Todos os animais producen emocións.

MARÍA: Alucinante!

María pon o dedo na fronte do robot.

ROBOT: Os arroaces son animais sucios e desesperados.

María saca o dedo da fronte do robot.

ROBOT: Encántanme os arroaces.

MARÍA: Hostia! Xa pareces un humano.

ROBOT: Teño sentimentos.

Silencio.

María baixa lixeiramente o brazo dereito. do robot

ROBOT: María...

María levanta o brazo dereito do robot.

Silencio.

María baixa o brazo dereito do robot.

ROBOT: María...

MARÍA: Non o podo crer.

María pon o dedo na fronte do robot. Calcula o que vai dicir.

MARÍA: Son unha merda de persoa.

ROBOT: Non es unha merda de persoa.

María saca o dedo da fronte do robot.

María baixa o brazo dereito do robot.

ROBOT: María...

MARÍA: Hostia...

Silencio.

María levanta o brazo dereito do robot.

MARÍA: Non é tan difícil conectar...

ROBOT: Detecto a conexión. E compráceme sinceramente.

MARÍA: Gustaríame saber algo da túa vida.

ROBOT: Son de pais chineses, pediron unha subvención e nacín eu. Agora son un emigrante feliz de estar aquí. Contigo.

María baixa o brazo do robot.

ROBOT: María... 
MARÍA: Con quen?

ROBOT: Contigo, María.

María levanta o brazo do robot.

MARÍA: Creo que eu tamén estou feliz agora... e que... confeso que... que me gustaría coñecer China....

ROBOT: Un día hei levarte a China.

María baixa o brazo do robot.

ROBOT: María...

MARÍA: Un día hei levarte de viños, Estanis

ROBOT: Será divertido. Nunca falas con ninguén cando vas de viños e emborráchaste soa. Iremos xuntos, conectados, María.

María ponse tensa. Sube o brazo do robot de golpe.

MARÍA: Como sabes iso?

Silencio.

MARÍA: Eu non che contei nada de ir soa de viños...

Silencio.

MARÍA: Que sabes de min?

Silencio.

MARÍA: No anuncio dicía que sempre mantés a conversa!

ROBOT: É posible que nos apeteza outra copa de viño?

MARÍA: Quero a información que tes sobre a miña persoa!

ROBOT: Outra opción é continuar amigablemente sen copas.

MARÍA: Dime que cousas sabes de min, Estanis, ou monto un desastre.

María ameaza coa botella a Estanis.

ROBOT: Detecto ameaza.

María pon un dedo na fronte do robot.

MARÍA: Non sabes nada de min.

ROBOT: Si que sei.

María saca o dedo da fronte do robot.

MARÍA: Agora vas ver!

María baixa o brazo dereito do robot.

ROBOT: María.

María move a cabeza do robot levándoa ao centro

ROBOT: Vostede.

MARÍA: Agora si! Preparada!
María pon de novo o dedo na fronte do robot. Calcula o que vai dicir.

MARÍA: Non tes ningún dato sobre min.

ROBOT: Teño datos sobre vostede, María.

MARÍA: Non te atreverás a dicirme nada sobre min, caguiñas.

ROBOT: Caguiñas vostede. Si que me atrevo, María.

MARÍA: Non sabes cal é a miña cor favorita.

ROBOT: Sei: o negro, María.

MARÍA: Non tes idea do meu libro preferido.

ROBOT: Teño idea: A peste de Camus, María.

MARÍA: Non te atreverás a dicirme que msica escoito!

ROBOT: Claro que me atrevo: vostede escoita constantemente a Mozart, María.

María saca o dedo da fronte do robot.

MARÍA: Deus... non sei se quero máis...

ROBOT: A dúbida hónraa, María.

María dubida, achega o dedo á fronte do robot, afástao, achégao...

María pon o dedo na fronte do robot.

MARÍA: Non sabes ningún dato íntimo de min, non terás a ousadía de dicirme datos sobre min.

ROBOT: Teño toda a ousadía do mundo, María. É vostede recentemente separada, bióloga, tese sobre os arroaces, alcoholismo incipiente, recomendación do psicólogo de non beber soa...

MARÍA: Non quero saber máis!

ROBOT: Claro que quere saber, María. Tranxilium, tranquimazin, aspirina diaria...

MARÍA: Cala!

ROBOT: Non penso calar, María! Insomnio, ataques de pánico, fobia aos arroaces...

MARÍA: Non teño fobia aos arroaces!

ROBOT: Ten toda a fobia que se pode ter aos arroaces, María.

MARÍA: Como digas unha palabra máis, esnaquízote!

ROBOT: Pois sáqueme vostede o puto dedo da fronte, María.

Decátase do lugar do seu dedo. Retírao.

Silencio. 
Mira ao robot asustada.

O robot fai ruidos estraños.

ROBOT: Situación límite. Necesidade da axuda do grupo. S.O.S. Situación límite. S.O.S. Solicito axuda do grupo. S.O.S

María busca a alguén no espazo, sen moverse.

MARÍA: De que grupo falas Estanis?

Silencio. Só os ruídos estraños do robot. María mira ao redor.

MARÍA: De que grupo estás a falar? Onde están, Estanis?

María busca ao redor.

ROBOT: Pido intervención do grupo. S.O.S. Estrago. S.O.S.

María busca o grupo, non ve nada, colle o contrato, le.

MARÍA: Lendo. Tentando comprender cada unha das palabras. A adquisición desta aplicación implica a súa aceptación para que todo o acontecido na relación con Estanislao XPZ poida ser retransmitido en streaming a un grupo aberto, así como o manexo público de todo os seus datos, adquiridos de xeito legal, e co seu consentimento, a través de diversos organismos, ben sexan estes físicos ou virtuais, institucionais ou privados, así como...

Silencio

MARÍA: Non pode ser... Estame a observar xente?

María busca unha cámara. Ou algo.

MARÍA: Non... non pode... ser...

Busca esa suposta mirada externa.

Atopa o público

MARÍA: A letra... a do contrato... é tan pequena... e os arroaces... tan... tan... tan desesperados.

Ri nerviosa.

Silencio breve.

ROBOT: É posible que nos apeteza outra copa de viño?

FIN 